\title{
Níveis de cromo orgânico em rações para frangos de corte mantidos sob estresse por calor no período de um a 42 dias de idade
}

[Levels of dietary chromiumin rations for male broilers kept under heat stress from one to 42 days of age]

\author{
R.G.M.V. Vaz $^{1}$, R.F.M. Oliveira $^{2}$, J.L. Donzele ${ }^{2}$, L.F.T. Albino ${ }^{2}$, W.P. Oliveira $^{3}$, B.A.N. Silva ${ }^{4}$ \\ ${ }^{1}$ Universidade de Rondônia - Porto Velho, RO \\ ${ }^{2}$ Departamento de Zootecnia - UFV - Viçosa, MG \\ ${ }^{3}$ Aluno de graduação - Bolsista PIBIC - UFV - Viçosa, MG \\ ${ }^{4}$ Aluno de pós-graduação - UFV - Viçosa, MG
}

\begin{abstract}
RESUMO
Avaliou-se o efeito da suplementação de cromo sobre o desempenho e o rendimento de cortes de frangos, mantidos em ambiente de alta temperatura, no período de um a 42 dias de idade. Foram utilizados 400 frangos de corte, machos, da linhagem Cobb, em um delineamento experimental inteiramente ao acaso, com cinco tratamentos, $0,350,700,1.050$ e $1.400 \mathrm{ppb}$ de cromo na ração, oito repetições e 10 aves por repetição. Nos períodos de um a 21 e de um a 42 dias de idade, não houve influência dos tratamentos sobre o ganho de peso, o consumo de ração e a conversão alimentar das aves, mas observou-se que o consumo de cromo aumentou de forma linear. Os tratamentos não influenciaram os pesos absoluto e relativo de nenhum dos cortes, peito, coxa e sobrecoxa, avaliados aos 42 dias de idade. A suplementação de até $1.400 \mathrm{ppb}$ de cromo na ração não influenciou o desempenho e o rendimento de cortes nobres de frangos de corte mantidos em estresse por calor, no período de um a 42 dias de idade.
\end{abstract}

Palavras-chave: frango de corte, consumo, estresse térmico, ganho de peso, mineral orgânico

\begin{abstract}
The effect of dietary organic chromium supplementation on the performance and yield of prime cuts of male broilers from one to 42 days of age reared under high environmental temperature was evaluated. Four-hundred Cobb male broilers, averaging $38 \pm 0.14 \mathrm{~g}$ were distributed in a simple sample random design with five treatments (0; 350; 700; 1,050; and 1,400ppb of chromium in ration), eight replicates, and ten birds per replicates. In periods from one to 21 and from one to 42 days of age, the treatments did not influence the weight gain, the food intake, and the feed:gain ratio of the birds. However, the chromium intake increased in a linear way. No effect of both absolute and relative weights of all evaluated cuts (breast, thigh, and drumstick) was observed. The dietary chromium supplementation up to 1,400ppb did not influence the performance and the carcass traits of the male broilers kept under heat stress from one to 42 days of age.
\end{abstract}

Keywords: male broiler, intake, heat stress, organic mineral, weight gain

\section{INTRODUÇ̃̃O}

O ambiente térmico em que os frangos são mantidos influencia seu crescimento. Segundo Pelicano et al. (2005), a elevada temperatura ambiente reduz o ganho de peso de frangos de corte a partir do $21^{\circ}$ dia de idade. Segundo
Pelicano et al. (2005), a temperatura ambiente elevada reduz o ganho de peso de frangos de corte a partir do $21^{\circ}$ dia de idade. A diminuição na taxa de crescimento decorrente da alta temperatura tem sido atribuída a mudanças no consumo de ração (Howlider e Rose, 1987; Sinurat et al., 1987) que, por sua vez, é

Recebido em 27 de maio de 2008

Aceito em 4 de fevereiro de 2009

E-mail: robertavaz@lycos.com

Apoio: $\mathrm{CNPq}$ 
inversamente relacionada à temperatura ambiente (Suk e Washburn, 1995). Howlider e Rose (1987) observaram que a redução no crescimento não acompanha a diminuição no consumo de alimento, sugerindo que outros fatores além do consumo de alimentos modificam a taxa de crescimento de frangos sob alta temperatura ambiente. Segundo Mazzi et al. (2002), esforços para aliviar o efeito do calor em frangos têm focado, entre outros aspectos, a inclusão de aditivos na dieta como forma de melhorar a resistência ao calor.

A suplementação com cromo tem efeito positivo no crescimento e na eficiência alimentar de aves sob condições de estresse ambiental (Lien et al., 1999; Sahin et al., 2001). Outro aspecto positivo da suplementação de cromo à ração é o de que, além de ser considerado nutricionalmente essencial para frangos e humanos (Sahin et al., 2003), é excessivamente excretado quando as aves são submetidas a estresse por calor (Smith e Teeter, 1987). O principal papel do cromo no metabolismo é potencializar a ação da insulina por sua presença na molécula organometálica, chamada fator de tolerância à glicose (GTF) (Sahin et al., 2003). O metabolismo da insulina influencia na peroxidação de lipídios, e o cromo, como um cofator da insulina, estaria agindo como antioxidante. Além disso, é considerado essencial para ativar certas enzimas e estabilizar proteínas e ácidos nucleicos.

A deficiência de cromo no organismo pode influenciar o metabolismo de carboidratos e de proteínas, reduzindo a sensibilidade à insulina nos tecidos periféricos e modificando a taxa de crescimento das aves (Sahin et al., 2003).

O objetivo desse estudo foi avaliar o efeito da adição de cromo orgânico na ração sobre o desempenho e o rendimento de cortes nobres, peito, coxa e sobrecoxa, de frangos de corte mantidos em ambiente de alta temperatura no período de um a 42 dias de idade.

\section{MATERIAL E MÉTODOS}

Foram utilizados 400 frangos de corte, machos, da linhagem Cobb, com peso inicial de $38 \pm 0,14 \mathrm{~g}$, vacinados contra as doenças de Marek e bouba aviária, durante o período de um a 42 dias de idade. $\mathrm{O}$ delineamento experimental utilizado foi o inteiramente ao acaso, com cinco tratamentos, 0,$0 ; 350 ; 700 ; 1.050 ; 1.400 \mathrm{ppb}$ de cromo, oito repetições e 10 aves por repetição.

As aves foram alojadas em gaiolas com piso telado, de área igual a $0,72 \mathrm{~m}^{2}$, dotadas de comedouros e bebedouros tipo calha, onde foram mantidas em condições de conforto térmico até o sétimo dia de idade, de acordo com as recomendações do manual da linhagem. A partir do oitavo e até o $42^{\circ}$ dia de idade, foram mantidas em condições de estresse por calor.

A temperatura interna da sala durante o período de oito a 21 dias foi mantida em $33,3 \pm 1,3^{\circ} \mathrm{C}$ e a umidade relativa em $63,6 \pm 6,1 \%$, correspondendo ao índice de temperatura de globo e umidade (ITGU) calculado de $84,1 \pm 1,2$. No período de 22 a 42 dias de idade, a temperatura foi mantida em $32,3 \pm 1,1^{\circ} \mathrm{C}$ e a umidade relativa em $64,1 \pm 4,3 \%$, correspondendo a um ITGU calculado de $82,9 \pm 1,0$.

O programa de luz adotado foi o contínuo, 24 horas de luz artificial, utilizando-se lâmpadas fluorescentes de 75 watts. $\mathrm{O}$ monitoramento da temperatura e da umidade relativa do ar foi feito por meio de termômetros de máxima e mínima, de bulbos seco e úmido e de globo negro instalados no centro da sala. As leituras dos termômetros foram realizadas diariamente, três vezes ao dia, às 8, 13 e 18h. Esses dados foram, posteriormente, convertidos em índice de temperatura de globo e umidade (ITGU), conforme proposto por Buffington et al. (1981).

Os tratamentos consistiram de uma ração basal (Tab. 1), à base de milho e farelo de soja, suplementada com minerais e vitaminas, formulada para atender às exigências das aves nas fases de um a 21 e de 22 a 42 dias de idade, segundo recomendações de Rostagno et al. (2000). A ração basal foi suplementada com cromo-metionina, $0,1 \%$ de $\mathrm{Cr}$ no produto, em substituição ao inerte, caulim, obtendo-se os níveis de 350, 700, 1.050 e 1.400ppb de cromo. $\mathrm{O}$ fornecimento de ração e água foi à vontade, sendo a água trocada três vezes ao dia para evitar seu aquecimento. 
Tabela 1. Composição centesimal e calculada das rações experimentais fornecidas às aves nos períodos de um a 21 e de 22 a 42 dias de idade

\begin{tabular}{|c|c|c|}
\hline \multirow[t]{2}{*}{ Ingrediente (\%) } & \multicolumn{2}{|c|}{ Período (dias) } \\
\hline & 1 a 21 & 22 a 42 \\
\hline $\operatorname{Milho}^{1}(7,75 \%$ PB $)$ & 59,742 & 63,881 \\
\hline Farelo de $\operatorname{soja}^{1}(45,5 \%$ PB $)$ & 34,139 & 29,646 \\
\hline Óleo de soja & 1,820 & 2,529 \\
\hline Fosfato bicálcico & 1,823 & 1,614 \\
\hline Calcário & 0,991 & 0,937 \\
\hline Sal comum & 0,455 & 0,385 \\
\hline DL-Metionina & 0,235 & 0,205 \\
\hline L-Lisina-HCl & 0,204 & 0,214 \\
\hline Caulim & 0,200 & 0,200 \\
\hline Cloreto de colina ( $60 \%)$ & 0,125 & 0,125 \\
\hline Mistura mineral $^{2}$ & 0,050 & 0,050 \\
\hline Mistura vitamínica ${ }^{3}$ & 0,100 & 0,100 \\
\hline Virginiamicina & 0,055 & 0,055 \\
\hline Salinomicina ${ }^{4}$ & 0,050 & 0,050 \\
\hline BHT & 0,010 & 0,010 \\
\hline Cromo-metionina & 0,000 & 0,000 \\
\hline Total & 100,00 & 100,00 \\
\hline \multicolumn{3}{|l|}{ Composição calculada } \\
\hline Proteína bruta (\%) & 21,000 & 19,300 \\
\hline $\mathrm{EM}(\mathrm{kcal} / \mathrm{kg})$ & 3.000 & 3.100 \\
\hline Lisina total $(\%)$ & 1,258 & 1,151 \\
\hline Lisina digestível (\%) & 1,143 & 1,045 \\
\hline Metionina + cistina digestível (\%) & 0,807 & 0,741 \\
\hline Treonina digestível (\%) & 0,700 & 0,640 \\
\hline Triptofano digestível (\%) & 0,232 & 0,208 \\
\hline Cálcio (\%) & 0,960 & 0,874 \\
\hline Fósforo disponível (\%) & 0,450 & 0,406 \\
\hline Sódio (\%) & 0,222 & 0,192 \\
\hline
\end{tabular}

${ }^{1}$ Valor obtido no Laboratório de Nutrição Animal do DZO/UFV, de acordo com metodologia descrita por Silva (1990).

${ }^{2}$ Quantidade kg/produto: Fe, 100mg; Co, 2,0mg; Cu, 20,0mg; Mg, 160,0mg; Zn, 100,0mg; I, 2,0mg; q.s.p., 1.000g.

${ }^{3}$ Quantidade kg/ produto: vit.A, 10.000UI; vit.D3, 2.000UI; vit.E, 30UI; vit.B1, 2,0mg; vit.B2, 6,0mg; vit.B6, 4,0mg; vit.B12, 0,015mg; ác. pantotênico, $12,0 \mathrm{mg}$; biotina, $0,1 \mathrm{mg}$; vit.K3, 3,0mg; ác. fólico, $1,0 \mathrm{mg}$; ác. nicotínico, 50,0mg; Se, $0,25 \mathrm{mg}$; q.s.p., $1.000 \mathrm{~g}$.

${ }^{4}$ Coxistac $12 \%$. 
No $21^{\circ}$ dia, todas as aves foram pesadas para continuação do experimento. Nessa fase, utilizaram-se 280 frangos, distribuídos nos cinco tratamentos $(0,0 ; 350 ; 700 ; 1.050 ; 1.400 \mathrm{ppb}$ de cromo), com oito repetições e sete aves por repetição. As sete aves mantidas no experimento foram as mais próximas da média do peso $( \pm 10 \%)$ da gaiola.

O consumo de ração foi calculado pela diferença entre a quantidade fornecida e as quantidades de desperdício e sobra, pesadas do primeiro dia ao final de cada período experimental (de um a $21 \mathrm{e}$ um a 42 dias de idade). Para determinar o ganho de peso, as aves foram também pesadas no início e ao final de cada um dos períodos. Com base nos dados de consumo de ração e de ganho de peso, foi calculada a conversão alimentar das aves em cada fase estudada.

No $42^{\circ}$ dia, todas as repetições foram pesadas, e as três com peso mais próximo da média $( \pm 10 \%)$ foram mantidas em jejum alimentar de 12 horas. Em seguida, as aves foram abatidas para avaliação do rendimento de cortes nobres, peito, coxa e sobrecoxa.
As análises estatísticas foram realizadas utilizando-se o programa SAEG (Sistema..., 2000). A estimativa do melhor nível de adição de cromo na ração foi estabelecida por meio de modelos de regressão linear e/ou quadrática conforme o melhor ajuste.

\section{RESULTADOS E DISCUSSÃO}

As temperaturas médias de 33,3 e $32,3^{\circ} \mathrm{C}$ verificadas, respectivamente, nas fases de oito a 21 e de 22 a 42 dias de idade, caracterizaram um ambiente de estresse por calor para as aves. Segundo Abreu et al. (2007), a temperatura de conforto para aves entre a quarta e a sétima semanas de idade seria de, respectivamente, 23$26^{\circ} \mathrm{C}$ e $20^{\circ} \mathrm{C}$. Os valores de ITGU calculados médios de 84,1 e 82,9 , respectivamente, para as fase de oito a 21 e de 22 a 42 dias de idade, que caracterizaram os ambientes de calor neste estudo, foram mais altos que os de 80,5 e 77,8, definidos por Valerio et al. (2003a, b) como de ambiente de alta temperatura.

Os resultados de consumo de ração, ganho de peso, conversão alimentar e consumo de cromo nos períodos de um a 21 e de um a 42 dias de idade são apresentados na Tab. 2.

Tabela 2. Consumo de ração (CR), ganho de peso (GP), conversão alimentar (CA) e consumo de cromo (CCr) de frangos de corte, machos, nos períodos de um a 21 e de um a 42 dias de idade, mantidos em estresse por calor de acordo com a suplementação de cromo $(\mathrm{ppb})$ na ração

\begin{tabular}{|c|c|c|c|c|c|c|}
\hline Variável & 0 & 350 & 700 & 1.050 & 1.400 & $\mathrm{CV}$ \\
\hline & \multicolumn{6}{|c|}{1 aos 21 dias de idade } \\
\hline $\mathrm{CR}(\mathrm{g})$ & 874 & 885 & 875 & 913 & 877 & 4,73 \\
\hline GP (g) & 627 & 644 & 644 & 641 & 629 & 5,11 \\
\hline $\mathrm{CA}$ & 1,39 & 1,37 & 1,36 & 1,42 & 1,39 & 3,46 \\
\hline \multirow[t]{2}{*}{$\mathrm{CCr}^{1}(\mathrm{ppb})$} & 0,00 & 310 & 612 & 958 & 1227 & 5,19 \\
\hline & \multicolumn{6}{|c|}{1 aos 42 dias de idade } \\
\hline CR $(g)$ & 3012 & 2978 & 2941 & 2998 & 2979 & 4,50 \\
\hline GP (g) & 1763 & 1712 & 1692 & 1736 & 1719 & 3,43 \\
\hline CA & 1,71 & 1,74 & 1,74 & 1,73 & 1,73 & 3,54 \\
\hline $\mathrm{CCr}^{1}(\mathrm{ppb})$ & 0,00 & 1042 & 2059 & 3148 & 4171 & 4,47 \\
\hline
\end{tabular}

${ }^{\mathrm{T}}$ Efeito linear $(\mathrm{P}<0,01)$.

No período de um a 21 dias de idade, não houve efeito $(\mathrm{P}>0,05)$ dos tratamentos sobre nenhuma das características estudadas. Estes resultados assemelham-se aos obtidos por Rosebrough e Steele (1981), que também não observaram efeito da adição de cromo na ração sobre a conversão alimentar de perus de um a 21 dias de idade, mantidos em ambiente com temperatura de $37^{\circ} \mathrm{C}$. Contudo, diferem dos encontrados por Sahin et al. (2003), que, em estudo com frangos de corte de um a 21 dias de idade, observaram que a adição de 400ppb de cromo na ração 
promoveu melhora no ganho de peso e na conversão alimentar quando as aves foram criadas em ambiente de alta temperatura.

Os tratamentos influenciaram $(\mathrm{P}<0,01)$ o consumo de cromo, que aumentou de forma linear segundo a equação: $\mathrm{C} \hat{\mathrm{C}} \mathrm{r}=0,441329+0,886866 \mathrm{Cr}\left(\mathrm{r}^{2}=\right.$ $0,99)$. O fato de não ter ocorrido variação significativa do consumo de ração (CR) entre os tratamentos justifica a relação direta verificada entre o consumo de cromo e sua concentração na ração.

No período total, um a 42 dias de idade, não se observou efeito $(\mathrm{P}>0,05)$ dos tratamentos sobre o consumo de ração, o ganho de peso e a conversão alimentar, mas o consumo de cromo aumentou $(\mathrm{P}<0,01)$ de forma linear segundo a equação: $\mathrm{C} \hat{\mathrm{C}} \mathrm{r}$ $=-6,05838+2,98507 \mathrm{X}\left(\mathrm{r}^{2}=0,99\right)$. Amatya et al. (2004) não constataram efeito da suplementação de cromo sobre nenhum dos parâmetros de desempenho de frangos de corte mantidos em ambiente de alta temperatura.

Estes resultados diferem dos verificados por Sahin et al. (2003), que, ao avaliarem rações suplementadas com 400ppb de cromo na forma de picolinato de cromo (CrPic) para frangos de corte, mantidos em estresse por calor, constataram aumento no consumo de ração e no ganho de peso e redução na conversão alimentar aos 21 e 42 dias de idade. Em estudo similar com codornas japonesas, mantidas em estresse por calor, Sahin et al. (2002b) também verificaram aumento linear no consumo de ração, no ganho de peso e na conversão alimentar das aves como consequência do aumento da concentração de $\mathrm{CrPic}$ na ração até o nível de $1.200 \mathrm{ppb}$.

Efeito positivo da suplementação de cromo sobre o consumo voluntário de alimento e o ganho de peso de frangos de corte e de codornas japonesas mantidas sob alta temperatura foi observado, respectivamente, por Lien et al. (1999) e Sahin et al. (2002a). Em condições de termoneutralidade, Kroliczwsa et al. (2004) e Ahmed et al. (2005) verificaram melhora do desempenho de frangos de corte em razão da suplementação de cromo na ração.

Com os resultados de conversão alimentar obtidos neste estudo, não ficou evidenciado o efeito positivo da suplementação de cromo na digestibilidade dos nutrientes da ração, conforme relataram Amatya et al. (2004) e Ahmed et al. (2005).

A inconsistência de resultados entre os trabalhos pode estar relacionada, entre outros fatores, à diferença no status imunológico das aves utilizadas nos diferentes estudos. Muck et al. (1984) evidenciaram que a suplementação de cromo pode amenizar a imunodepressão induzida pelo cortisol, cuja produção é aumentada nos animais em situação de estresse. Estudos posteriores confirmaram que a suplementação de cromo reduziu a concentração de cortisol (Chang e Mowat, 1992) e aumentou a produção de anticorpos (Burton et al., 1993) em aves sob estresse.

Ainda, com relação aos efeitos positivos da suplementação de cromo sobre o sistema imunológico de animais sob estresse, Chatterjee et al. (1973) constataram aumento na concentração de vitamina $\mathrm{C}$ no baço de frangos, enquanto Sahin et al. (2003) verificaram aumento nas concentrações plasmáticas das vitaminas $\mathrm{C}$ e $\mathrm{E}$ em aves submetidas ao estresse por calor, em razão da suplementação de cromo nas rações. Essas proposições são consistentes com o relato de Ahmed et al. (2005), em que a resposta positiva das aves à suplementação de cromo está relacionada, entre outros fatores, à melhora da sua imunocompetência.

Os resultados dos pesos absoluto e relativo dos cortes nobres, peito, coxa e sobrecoxa, dos frangos de corte aos 42 dias de idade mantidos em ambiente de alta temperatura são mostrados na Tab. 3 .

Não se verificou efeito $(\mathrm{P}>0,05)$ da suplementação de cromo sobre os pesos absoluto e relativo de nenhum dos cortes nobres avaliados, o que está coerente com os resultados obtidos por Amatya et al. (2004), que não constataram variação significativa na deposição de proteína e gordura na carcaça de frangos de corte mantidos sob alta temperatura devido à suplementação de cromo na ração. Os resultados do presente estudo não comprovaram os possíveis efeitos positivos da suplementação de cromo sobre o peso e o rendimento de peito de aves submetidas a estresse por calor, atribuídos à sua possível ação na redução da síntese de corticosterona, conforme proposição de Sahin et al. (2003).

Em estudos realizados com suínos, Evock-Clover et al. (1993) e Mathews et al. (2005) também não verificaram efeito da suplementação de cromo na ração sobre o desempenho e as características da carcaça de suínos em crescimento e em terminação. 
Níveis de cromo orgânico...

Tabela 3. Pesos absoluto e relativo de cortes nobres - peito, coxa e sobrecoxa - de frangos de corte machos aos 42 dias de idade, mantidos em estresse por calor de acordo com a suplementação de cromo (ppb) na ração

\begin{tabular}{lcccccc}
\multicolumn{1}{r}{ Variável } & 0 & 350 & 700 & 1.050 & 1.400 & CV $(\%)$ \\
\hline \multirow{2}{*}{ Peito } & & \multicolumn{5}{c}{ Peso absoluto (g) } \\
Coxa & 418 & 419 & 408 & 426 & 433 & 7,44 \\
Sobrecoxa & 207 & 205 & 208 & 205 & 206 & 7,62 \\
\hline \multirow{2}{*}{ Peito } & 223 & 220 & 210 & 221 & 213 & 8,79 \\
Coxa & 27,81 & 27,97 & 27,47 & 28,25 & 28,40 & 4,89 \\
Sobrecoxa & 13,73 & 13,73 & 14,01 & 13,56 & 13,50 & 4,21 \\
\hline
\end{tabular}

\section{CONCLUSÕES}

Os níveis de cromo testados $(350,700,1.050$ e $1.400 \mathrm{ppb})$ não influenciaram o desempenho e as características de carcaça de frangos de corte mantidos em estresse por calor no período de um a 42 dias de idade.

\section{REFERÊNCIAS BIBLIOGRÁFICAS}

ABREU, P.G.; ABREU, V.M.N.; COLDEBELLA, A. et al. Condições térmicas ambientais e desempenho de aves criadas em aviários com e sem o uso de forro. Arq. Bras. Med. Vet. Zootec., v.59, p.1014-1020, 2007.

AHMED, N.; HALDAR, S.; PAKHIRA, M.C. et al. Growth performances, nutrient utilization and carcass traits in broiler chickens fed with a normal and a low energy diet supplemented with organic chromium (as chromium chloride hexahydrate) and a combination of inorganic chromium and ascorbic acid. J. Agric. Sci., v.143, p.427-439, 2005.

AMATYA, J.L.; HALDART, S.; GHOSH, T.K. Effects of chromium supplementation fram inorganic and organic sources on nutrient utilization, mineral metabolism and meat quality in broiler chickens exposed to natural heat stress. Anim. Sci., v.79, p.241-253, 2004.

BUFFINGTON, D.E.; COLAZZO-AROCHO, A.; CANTON, G.H. et al. Black globe-humidity index (BGHI) as comfort equation for dairy cows. Trans. ASAE, v.24, p.711-714, 1981.

BURTON, J.L.; MALLARD,B.A.; MOWAT, D.N. Effects of supplemental chromium on immune response of periparturiente and early lactation dairy cows. J. Anim. Sci., v.71, p.15321539, 1993.

CHANG, X.; MOWAT, D.N. Supplemental chromium for stressed and growing feeder calves. J. Anim. Sci., v.70, p.559-565, 1992.

CHATTERJEE, G.C.; ROY, R.K.; SASMAI, N. et al. Effect of chromium and tunsgsten on Lascorbic acid metabolism in rats and chicks. $J$. Nutr., v.103, p.509-514, 1973.

EVOCK-CLOVER, C.M.; POLANSKY, M.M.; ANDERSON, R.A. et al. Dietary chromium supllementation with or without somatotropin treatment alters serum hormones and metabolites in growing pigs without affecting growth performance. J. Nutr., v.123, p.1504-1512, 1993.

HOWLIDER, M.A.R.; ROSE, S.P. Temperature and the growth of broilers. World's Poult. Sci. J., v.43, p.228-237, 1987.

KRÓLICZEWSKA， B.; ZAWADZKI， W.; DOBRAZANSKI, Z. et al. Changes in selected serum parameters of broiler chicken fed supplemental chromium. J. Anim. Physiol. Anim. Nutr., v.88, p.393-400, 2004.

LIEN, T.H.; HOMG, Y.M.; YANG, K.H. Performance, serum characteristics, carcass traits and lipid metabolism of broilers as affect by supplement of chromium picolinate. Br. Poult. Sci., v.40, p.357-363, 1999.

MATTEWS, J.O; GUZIK, A.C.; LEMIEUX, F.M. et al. Effects of chromium proprionate on growth, carcass traits, and pork quality of 
growing-finishing pigs. J. Anim. Sci., v.83, p.858-862, 2005.

MAZZI, C.M.; FERRO, M.I.T.; COELHO, A.A.D. et al. Effect of heat exposure on the thermoregulatory responses of selected naked neck chickens. Arq. Bras. Med. Vet. Zootec., v.54, p.35-41, 2002.

MUCK, A.; GUYRE P.; HOLPROOK, N. Physiological function of glucorticoids in stress and their relation to pharmacological actions. Endocr. Rev., v.5, p.25-40, 1984.

PELICANO, E.R.L.; BERNAL, F.E.M.; FURLAN, R.L. et al. Efeito da temperatura ambiente e da restrição alimentar proteica ou energética sobre o ganho de peso e crescimento ósseo de frangos de corte. Arq. Bras. Med. Vet. Zootec., v.57, p.353-360, 2005.

ROSEBROUGH, R.W.; STEELE, N.C. Effect of supplemental dietary chromium or nicotinic acid on carbohydrate metabolism during basal, starvation, and refeeding periods in poultries. Poult. Sci., v.60, p.407-417, 1981.

ROSTAGNO, H.S.; ALBINO, L.F.T.; DONZELE, J.L. et al. Tabelas brasileiras para aves e suínos: Composição de alimentos e exigências nutricionais. Viçosa: UFV, 2000. $141 \mathrm{p}$.

SAHIN, K.; KÜÇÜK, O.; SAHIN, N. Effects of dietary chromium picolinate supplementation on performance and plasma concentrations of insulin and costicosterone in laying hens under low ambient temperature. J. Anim. Physiol. Anim. Nutr., v.85, p.142-147, 2001.

SAHIN, K.; KÜÇÜK, O.; SAHIN, N. et al. Effects of vitamin $\mathrm{C}$ and vitamin $\mathrm{E}$ on lipid peroxidation, status, serum hormones, metabolite and mineral concentrations of japanese quails reared under heat stress $\left(34^{\circ} \mathrm{C}\right)$. Int. J. Vit. Nutr. Res., v.72, p.91-100, 2002a.

SAHIN, K.; OZBEY, O.; ONDERCI, M. et al. Supplementation can alleviate negative effects of heat stress on egg production, egg quality and some serum metabolites of laying Japanese quail. J. Nutr., v.132, p.1265-1268, 2002b.

SAHIN, K.; SAHIN, N.; KÜÇÜK, O. Effects of chromium and ascorbic acid supplementation on growth, carcass traits, serum metabolities, and antioxidant status of broiler chickens reared at a high environmental temperature $\left(32^{\circ} \mathrm{C}\right)$. Nutr. Res., v.23, p.225-238, 2003.

SILVA, D.J. Análise de alimentos: métodos químicos e biológicos. Viçosa, MG: UFV, 1990. $166 \mathrm{p}$.

SINURAT, A.P.; BALNAVE, D.; MCDOWELL, G.H. Growth performance and concentrations of thyroid hormones and growth hormone in plasma of broilers at high temperatures. Aust. J. Biol. Sci., v.40, p.443-450, 1987.

SISTEMAS de análises estatísticas - SAEG. Viçosa, MG: UFV, 2000. 150p.

SMITH, M.O.; TEETER. R.G. Potassium balance of the 5- to 8-week old broiler exposed to constant heat or cycling high temperature stress and the effects of supplemental potassium chloride on body weight gain and feed efficiency. Poult. Sci., v.66, p.487-492, 1987.

SUK, Y.O.; WASHBURN, K.W. Effects of environment on growth, efficiency of feed utilization, carcass fatness, and their association. Poult. Sci., v.74, p.285-296, 1995.

VALERIO, S.R.; OLIVEIRA, R.F.M.; DONZELE, J.L. et al. Níveis de lisina digestível em rações, em que se manteve ou não a relação aminoacídica para frangos de corte de 1 a 21 dias de idade, mantidos em estresse por calor. Rev. Bras. Zootec., v.32, p.361-371, 2003a.

VALERIO, S.R.; OLIVEIRA, R.F.M.; DONZELE, J.L. et al. Níveis de lisina digestível em rações, em que se manteve ou não a relação aminoacídica para frangos de corte de 22 a 42 dias de idade, mantidos em estresse por calor. Rev. Bras. Zootec., v.32, p.372-378, 2003 b. 